\title{
Lung Cancer Stem Cells: Current Progress and Future Perspectives
}

Rasha Salama, Joy Tang, Shirish M. Gadgeel, Aamir Ahmad* and Fazlul H. Sarkar*

Departments of Pathology and Oncology, Karmanos Cancer Institute, Wayne State University School of Medicine, Detroit, MI 48201, USA

\begin{abstract}
Cancer stem cells (CSCs) have attracted a lot of interest in the field of cancer research in recent years. Lung CSCs share many characteristics with the normal pluripotent stem cells, such as self-renewal and multi-potent abilities. Identification of normal adult lung stem cells and their response to injury has led us to the lung cancer stem cells, partially based on the knowledge that lung CSCs as well as the normal lung stem cells share similar markers and/or location in the airway tree. Several studies have identified CD133, CD44, ALDH (aldehyde dehydrogenase) and ABCG2 (ATP-binding cassette sub-family $G$ member 2) as lung cancer stem cell markers, all of which are validated CSC markers in multiple other cancer types as well. Embryogenesis signaling pathways, such as the hedgehog, wnt and notch pathways has also been implicated as determinants of lung CSC phenotype. With the central role of CSCs in tumor recurrence, metastasis and drug-resistance, targeting CSC markers and/or signaling pathways to eradicate lung cancer and enhance patient outcome is an attractive approach. This review summarizes our current understanding of CSC markers and signaling pathways in lung cancer.
\end{abstract}

Keywords: Lung cancer; Cancer stem cells; CD133; CD44; ALDH; ABCG2; Notch; Wnt; Shh

\section{Introduction}

Lung cancer is one of the most common malignancy in the US and worldwide and a leading cause of cancer-related deaths [1]. Lung cancer consists of heterogeneous groups in terms of pathological features and is classified into the following two major types, Small Cell Lung Carcinoma (SCLC) and Non-Small Cell Lung Carcinoma (NSCLC). NSCLC includes squamous cell carcinoma and adenocarcinoma.

It is believed that the existence of Cancer Stem Cells (CSCs) within the tumors is responsible for the majority of biological characteristics that are associated with aggressive behavior of tumors/ cancer cells. CSC theory proposes that a tumor cell subpopulation has self-renewal capacity, cancer-initiating ability and multi-potent differentiation ability. In recent years, substantial experimental evidence has been reached in support of the role of CSCs. There are many concepts in cancer that can be explained by the stem cell theory like tumor self-renewal, tumor heterogeneity, and tumor relapse after treatment and resistance to conventional chemotherapies. CSCs were first described in human hematopoietic cancer. They have been studied in other solid tumors as well as in lung cancer [2-5]. Clinical specimens from SCLC and adenocarcinoma patients have been found to include a small subpopulation of cells $(<1.5 \%)$ that are capable of forming colonies when grown on agar. Upon their intracranial injection into athymic nude mice, they produced cancers with characteristics identical to those of the original specimens [5]. Researchers have used different methods in investigate cancer stem cells, such as flow cytometry, because CSCs express tissue-specific cell surface markers, for example, CD133, ALDH, ABCG2, and CD44. All of these will be discussed in this article. The ability of ABCG2, expressed in stem cell populations to efflux the fluorescent Hoechst 33342 dye, forms the basis for side population assay. Distinct "low" Hoechst 33342 dye staining pattern cells are the so called Side Population Cells (SPC). They have been described in a variety of tumor types as being enriched in stem-like properties [6]. SPC are also found to have the ability to self-renew in addition to having a high level of human telomerase reverse transcriptase (hTERT). Telomerase is an important marker of cellular immortalization in cancers [6].

CSCs are resistant to chemotherapeutic drugs and can be selected from the parental population of human lung tumor cells by treatment with drugs. Cells which survived drug treatment have all the properties of CSCs. They have been reported to possess high clonogenic efficiency, enrichment of SPC and expression of CD133 marker, all of which are associated with CSCs [7].

\section{Origin of Cancer Stem Cells}

The origin of CSCs is still hotly debated. One theory is the malignant transformation of normal stem cells particularly in rapidly dividing tissues, where the stem cell is available throughout life and it might accrue different mutations [8]. Epithelial-to-mesenchymal transition has been implicated in the origin of the CSCs in the breast, by acquiring cells with CD44high/CD24 low marker, which is a cancer stem marker [9]. In the search for the lung CSCs, studies began with looking for the normal lung stem cells [10-20] (Table 1). Due to the quiescence of the lung epithelia, identification of the lung stem cells has been more difficult than other tissues. Therefore, studies looked at the cell response to injury as a means to find if they have stem cell characteristics.

In the proximal airways, including the trachea and bronchi, a population of tracheal basal cells that express Keratin-14 [21] and Keratin-5 [22] has the ability to proliferate after injury and to give rise to multiple phenotypes. Studies have shown that squamous cell

*Corresponding authors: Aamir Ahmad, PhD, Departments of Pathology and Oncology, Karmanos Cancer Institute, Wayne State University School of Medicine 707 HWCRC Bldg, 4100 John R. Street, Detroit, MI 48201, USA, Tel: 313-5768315; Fax: 313-576-8389; E-mail: ahmada@karmanos.org

Fazlul H. Sarkar, PhD, Departments of Pathology and Oncology, Karmanos Cancer Institute, Wayne State University School of Medicine, 707 HWCRC Bldg 4100 John R. Street, Detroit, MI 48201, USA, Tel: 313-576-8315; Fax: 313-5768389; E-mail: fsarkar@med.wayne.edu

Received November 15, 2012; Accepted December 17, 2012; Published December 19, 2012

Citation: Salama R, Tang J, Gadgeel SM, Ahmad A, Sarkar FH (2012) Lung Cancer Stem Cells: Current Progress and Future Perspectives. J Stem Cell Res Ther S7:007. doi:10.4172/2157-7633.S7-007

Copyright: @ 2012 Salama R, et al. This is an open-access article distributed unde the terms of the Creative Commons Attribution License, which permits unrestricted use, distribution, and reproduction in any medium, provided the original author and source are credited. 


\begin{tabular}{|c|c|c|c|c|c|}
\hline Airway & $\begin{array}{l}\text { Cells capable of stem-like } \\
\text { behavior }\end{array}$ & Cell response to injury & Normal stem cell marker & Associated cancer & Cancer marker \\
\hline $\begin{array}{l}\text { Proximal airway (trachea } \\
\text { and Bronchi) }\end{array}$ & Basal cells [10] & $\begin{array}{l}\text { Self-renewal and multi- } \\
\text { potent abilities [11] }\end{array}$ & $\begin{array}{l}\text { Keratin } 5 \\
\text { Keratin14 } \\
\text { Transcription factor-63 } \\
\text { Trp-63 [12] }\end{array}$ & $\begin{array}{l}\text { Squamous cell } \\
\text { carcinoma }\end{array}$ & Keratin 5 [13] \\
\hline \multirow{3}{*}{$\begin{array}{l}\text { Midlevel airway } \\
\text { (Bronchioles) }\end{array}$} & Clara cells $[14]$ & $\begin{array}{l}\text { Multi-potent but not self- } \\
\text { renewal [14] }\end{array}$ & $\begin{array}{l}\text { Secretoglobin, scgb1a1 } \\
\text { (CCSP or CC10) [12] }\end{array}$ & & \\
\hline & Variant Clara cells [15] & $\begin{array}{l}\text { Multi-potent and self- } \\
\text { renewal [17] }\end{array}$ & $\begin{array}{l}\text { Lack cytochrome P4502F2 } \\
\text { [15] }\end{array}$ & Small cell lung cancer & $\begin{array}{l}\text { Calcitonin gene-related } \\
\text { peptide }\end{array}$ \\
\hline & $\begin{array}{l}\text { Pulmonary Neuroendocrine } \\
\text { Cells (PNEC) [16] }\end{array}$ & Self-renewal [17] & $\begin{array}{l}\text { Calcitonin gene-related } \\
\text { peptide [20] }\end{array}$ & & \\
\hline Distal airway (alveoli) & $\begin{array}{l}\text { Bronchoalveolar duct junction } \\
\text { cell }\end{array}$ & Self-renewal [18] & $\operatorname{CCSP}[19]$ & $\begin{array}{l}\text { Bronchiolar } \\
\text { adenocarcinoma }\end{array}$ & \\
\hline
\end{tabular}

Table 1: Normal lung stem cells and associated lung cancer.

carcinoma frequently arises in the proximal part of the airways and expresses Keratin 5 [13]. In the middle airway, Clara cells, which serve to protect and detoxify the bronchiolar epithelium, have been suggested by some to be progenitor cells [23] due to their role in maintenance of both secretory and ciliated cell types after oxidant-mediated damage. Clara cells also possess multi-potent capacity for differentiation. However, it is believed that most Clara cells do not possess the ability to self-renew [20]. Pulmonary Neuroendocrine Cells (PNEC) is specialized airway epithelial cells that produce specific neuropeptides and are grouped in clusters, termed Neuroepithelial Bodies (NEBs). Repair from airway injury is associated with PNEC hyperplasia [16]. However, PNEC do not have multi-potent differentiation ability [24]. SCLC, which frequently arises in the midlevel bronchioles, has been shown to express stem cell marker CD44 [13]. Moreover, similarly to PNECs, SCLC exhibits primitive neuroendocrine features, such as the expression of calcitonin gene-related peptide [24]. In the distal airways, including terminal bronchioles and alveoli, cells in the bronchoalveolar duct junction have been found to give rise to diverse populations of cells after injury [19]. Lung adenocarcinoma and bronchoalveolar carcinoma have been associated with stem cells from the bronchoalveolar duct junction region [19].

Stemness phenotype model theory suggests that all cancer cells have stem cell properties, and that the stemness is modulated by microenvironment [25]. This type of analysis suggests that stem cells should be constantly generated in order to not disappear after continuous passages. One of the main proposals of this theory is that all cancer cell phenotypes must originate from one mother cell. This clonal origin likely to be the case for the A549 cell line [26]. The stemness phenotype theory proposes that all CSCs and non-CSC should undergo symmetrical division and then comes the role of the microenvironment to change the phenotype of the cell [26]. It has been demonstrated that ectopic expression of miR-17-92, which is present in embryonic stem cells, promotes proliferation and influences differentiation of lung epithelial progenitor cells [20]. Matrixmetalloproteinase-10 (MMP10) (stromelysin 2) has been shown to have a role in the maintenance and tumorigenicity of mouse lung CSCs. Moreover, it has been shown that this tumorigenicity is independent of MMP10 in the tumor microenvironment. It is rather more dependent on MMP10 produced by cancer cells [27].

Epithelial-to-Mesenchymal Transition (EMT) is a complex program by which epithelial cells lose their characteristics, such as cell-to-cell adhesion, polarity and lack of motility. The cells also gain mesenchymal features, including motility and resistance to apoptosis. EMT role in acquisition of stem cell characteristics has been studied in mammary epithelial cells [9] and other solid tumors [28,29]. However, in the lung, EMT and CSCs are still not adequately evaluated. EMT signaling pathways, such as Wnt, Notch and Hedgehog, are also involved in normal and cancerous stem cell renewal and maintenance [30]. Our own work on TGF- $\beta$-induced EMT in NSCLC cells has demonstrated a role of sonic hedgehog (Shh) signaling [31]. Another study found that after four weeks of exposure of immortalized human bronchial epithelial cells to tobacco carcinogens, EMT was demonstrated by reduced expression of E-cadherin and increased expression of ZEB1 (Zinc finger E-box-binding homeobox 1) beside the change in cells morphology, while it took the cells 12 weeks to gain stem cell-like traits like CD44 high/CD24 low marker and spheroids formation [32].

\section{Role of Microenvironment}

Stem cell populations are established in niches, which represent the microenvironment that interacts with stem cells to regulate stem cell self-renewal and differentiation. It remains unclear whether CSCs form their own microenvironment or take advantage of the pre-existing tissue environment [33]. The solid microenvironment is comprised of different mesenchymal cell types that are recruited by cancer cells to enhance their survival, growth, invasion and dissemination. These include endothelial cells of the blood and lymphatic circulation, inflammatory cells, fibroblasts and others [34]. Fibroblasts are known to produce different chemokines that modulate tumor expansion, invasion, angiogenesis, and activation of extracellular matrixassociated cytokines and growth factors. Some of them are commonly associated with self-renewal [33,35].

It has been suggested that Mesenchymal Stem Cells (MSC) in the bone marrow travel to the tumor site [36] when attracted by chemoattractive molecules, such as SDF-1 (stromal cell-derived factor-1), SCF (stem cell factor)/c-kit, VEGF/VEGFR (vascular endothelial growth factor/vascular endothelial growth factor receptor) and others [37]. In the tumor sites, they play different roles, including contribution to blood vessel formation [38], immunomodulation [38] and promotion of metastatic behavior as established in breast cancer cells when mixed together with the MSCs [39]. However, MSC may suppress the tumor through downregulation of Wnt signaling pathway in breast cancer [40]. In addition to these cells, the solid microenvironment also contains factors secreted into the bloodstream, which also influences the tumor cell proliferation and differentiation. These include TGF- $\beta$, which is involved in maintenance of stem cell phenotypes and the EMT [41], Platelet-Derived Growth Factor (PDGF), fibroblast growth factor, insulin like growth factor-1, and epidermal growth factor [33].

\section{Lung CSC Markers}

Currently, there are relatively few CSC markers that have been validated. However, extensive studies have led to the identification 
of various CSCs that differ from other cells in the tumor. Most CSCs express multiple markers at the same time and using one marker to define CSC is not possible. For example in cell lines A549 and H446, CD133 positive and negative populations contain the same amount of CSCs [42]. Studying CSC markers may present new insight that will improve current lung cancer therapy and better patient prognosis. In this review we will highlight the current knowledge for some of the markers.

\section{CD133}

CD133 is the most frequently demonstrated marker for CSCs. It is a cell surface glycoprotein that consists of five transmembrane domains and two large glycosylated extracellular loops. Chen et al. [43] studied CD133 positive cells and CD133 negative cells from tissue samples of 10 NSCLC patients and cell lines A549, H1299, CCL-1, CCL-5 and C299. Results showed that CD133 positive cells displayed higher ability of self-renewal, tumor initiation and drug resistance. They also expressed higher level of Oct-4 (octamer-binding transcription factor 4) [43], which is a transcription factor expressed in embryonic stem cells [44]. Another study demonstrated that exposing A549 cells to cytotoxic concentration of cisplatin resulted in an eight-fold increase of CD133 cells fraction [45]. This study also confirmed the findings in vivo using mice with six different lung cancer xenografts that were treated with cisplatin, which supports the idea that chemotherapy is not effective in eliminating CD133 positive cancer initiating cells. Investigation of the CD133 in the human lung cancer cell lines A549, H157, Hee6, Calu-1, H292 and H446 showed that CD133 cell expressing stem cell characteristics were found only in H446 SCLC, but CD133 positive cells were not found in other NSCLC cell lines [46]. In another study, increased levels of CD133-expressing cells were found in NSCLC specimens, where they seemed to contribute to vasculogenesis [47]. However, in resected early stage NSCLC, CD133 had no prognostic value [48].

\section{ALDH}

Aldehyde Dehydrogenase (ALDH) is another marker connected with stem cell-like properties. Its enzymes are responsible for acetaldehyde oxidation and control the differentiation of normal stem cells [49]. ALDH-1 has been suggested as the specific marker for human lung adenocarcinoma [50]. Another study showed that ALDH1A1 positive lung cancer cells displayed resistance to gefitinib, an EGFR (epidermal growth factor receptor) tyrosine kinase inhibitor, compared to ALDH1A1 negative lung cancer cells [51]. Unlike CD133, increased cancer stem cell ALDH has been found to be helpful in tumor staging and provided prognostic information [52]. Another study demonstrated that there is also a correlation between ALDH1A1 and poor patient prognosis [53]. Analysis of various lung cancer cell lines and tumors reported that the majority of NSCLC comprise of a subpopulation of cells with increased ALDH activity, which is associated with the expression of ALDH1A1. Furthermore, lung cancer cells that expressed ALDH were shown to be highly tumorigenic and clonogenic in addition to being capable of self-renewal in comparison to lung cancer cells that do not express ALDH. The same study also revealed that there was increased expression of the Notch pathway transcript in $\mathrm{ALDH}^{+}$lung cancer cells. Suppressing the Notch pathway resulted in a considerable decrease in $\mathrm{ALDH}^{+}$cells, tumor cell proliferation and cell clonogenicity [53]. These insights suggest that ALDH functions in selecting for a subpopulation of self-renewing NSCLC stem-like cells with a greater possibility of being tumorigenic. Further exploration of the Notch pathway and the ALDH component in lung cancer may yield more insight into lung cancer stem cell maintenance.

\section{ABCG2}

ABCG2 is an ATP binding cassette transporter, which can pump chemotherapeutic drugs out of the cell, resulting in decreased concentrations of drugs inside the cell [54]. ABCG2 uses energy from ATP to drive the transport of substances across the cell membrane, including drug metabolites and other compounds. It is highly expressed in a subpopulation of stem cells and further research suggests that there is a link between ABCG2 and unfavorable prognosis in various tumors [55]. Moreover, recent studies have shown that ABCG2 is expressed in many cancer stem cells, including lung cancer. Evidence indicates that ABCG2 functions in protecting stem cells and increase the survival of hematopoietic stem cells in hypoxia [56]. In addition, further studies found that ABCG2 plays a cytoprotective role in cardiac SP cell populations placed in oxidative stress and they also contribute to the proliferative capacity of human hematopoietic progenitors in vitro and in vivo [57]. Overall, ABCG2 observes a role in preserving stem cells by contributing to their survival ability and proliferation.

Stem cell isolation from six human lung cancer cell lines (H460, H23, HTB-58, A549, H441 and H2170), using flow cytometry and Hoechst 33342 dye efflux assay, showed a side population with elevated expression of ABCG2 and increased resistance to drugs [6]. It has been recently demonstrated that Low Molecular Weight Heparin (LMWH) reduced lung side population cell colony formation ability and ABCG2 expression. Furthermore, combination of LMWH and cisplatin could overcome drug resistance and induce apoptosis [58].

\section{CD44 and CD24}

CD44, which is a frequently studied cell surface marker, is a hyaluronic acid receptor that is expressed by almost every tumor cell [59]. It promotes cell migration and is generally associated with proteins that are critical in regulating cell adhesion, proliferation, growth, migration and motility [60]. Moreover, CD44 is associated with signaling cascades that stimulate tumor initiation. The CD44 gene also experiences alternative splicing to encode different proteins in varying cancer subtypes, which makes it an ideal surface marker for isolating CSCs from carcinomas [61]. CD24 is a heat stable antigen that is another cell surface marker expressed in numerous tumors. It plays a role in cell-to-cell and cell-to-matrix interactions and is also involved in cell adhesion and metastasis, which suggests that it may be an essential marker in tumor prognosis and diagnosis [62]. It also enhances cell proliferation and stimulates tumor cells to adhere to fibronectin, collagen and laminin. High levels of CD24 are usually associated with tumor progression and metastasis. CD44 and CD24 have been utilized together or with other markers to isolate CSCs from solid tumors, though their usage is restricted to a particular few cancer types due to their lack of universal expression [63]. In vitro and in vivo studies of CD44 positive lung cancer cells showed the ability of these cells to initiate tumors [64]. Moreover, CD44 positive cells were also associated with EMT markers, such as SNAI1 (snail homolog 1), CDH2 (cadherin 2) and VIM (vimentin), which lend more evidence to the role EMT may play in maintaining stemness.

\section{Role of Signaling Pathways in Lung CSCs}

Hh pathway, wnt pathway and Notch pathway regulate proliferation and differentiation during embryogenesis. It was hypothesized that the same pathways that rule normal stem cell self-renewal could also rule cancer stem cell self-renewal. In the following section we discuss these pathways in the context of lung CSCs. 


\section{Role of Hh pathway}

The Hedghog $(\mathrm{Hh})$ signaling pathway is activated when the Shh ligand binds to transmembrane patched (PTCH1) proteins. In the absence of the ligand, PTCH1 represses Smo (smoothened), which prevents the activation of Hedgehog. However, after binding of the sonic hedgehog ligand to PTCH1, the interaction of PTCH1 and Smo is altered and Smo is no longer inhibited. This in turn activates several members of the GLI family of transcription factors. SCLCs maintain their malignant phenotype in vitro and in vivo through liganddependent Hedgehog pathway activation [65]. The hedgehog-signaling pathway has been also shown to be activated in NSCLC and correlates with histological type and prognostic parameters [66].

The Hh pathway regulates many basic processes, such as stem cell maintenance, cell differentiation and cell proliferation. Activation of the Hh pathway has been shown to lead to tumorigenesis in many carcinomas, including lung cancer. In addition, paracrine Hh signaling has also been shown to regulate proliferation of CSCs and enhance proliferation and tumor invasion $[67,68]$. Research suggests that tumor growth and propagation are dependent on a small group of CSCs with similar characteristics to normal tissue stem cells and are thus regulated by the same signaling molecules [69]. Hh signaling is associated with the regulation of self-renewal of CSCs in several cancers, including lung cancer. Furthermore, it has been shown to induce tumor metastasis by contributing to EMT, which is the transforming of polarized epithelial cells into mesenchymal cells, which are more prone to invasive growth and metastasis. Through the up regulation of transcription factor SNAIL and the down regulation of E-cadherin, Hh helps induce EMT in numerous cell lines [70]. This is in agreement with our earlier results with the cell line A549 where induction of EMT by TGF- $\beta$ is marked by activation of Shh signaling [31]. Targeting the Hh signaling pathway may provide new therapeutic options for many different cancer types. Although the mechanisms behind the Hh signaling pathway is not completely understood, research has shown that aberrant Hh signaling does cause tumor growth and proliferation, increased tumor aggression and frequency of metastasis.

\section{Role of Wnt pathway}

Wnt signaling mediates many cellular processes, including proliferation, differentiation, apoptosis and motility [71]. The best understood Wnt signaling pathway is the canonical pathway, where Wnt ligands bind to a cell surface receptor complex causing the phosphorylation of disheveled family proteins (Dvl). The Dvl then activates GSK-3 (Glycogen Synthase Kinase 3) and CK1 (Casein Kinase 1 ), which mediates the degradation of $\beta$-catenin molecules, resulting in the accumulation of $\beta$-catenin in the cytoplasm. Some $\beta$-catenin is able to enter the nucleus and interact with TCF/LEF (Transcription Factor/ Lymphoid Enhancer-Binding Factor 1) family transcription factors to promote specific gene expression [72]. It has been shown that Wnt1 and Wnt2 are overexpressed in NSCLC cell lines and primary tumors [73].

Teng et al. [74] revealed regulation of a main regulator of selfrenewal and differentiation in embryonic stem cells, OCT-4, after treating lung cancer cell line A549 with cisplatin for two days. This was accompanied by an increased expression of $\beta$-catenin. When $\mathrm{LiCl}$, a GSK-3b inhibitor, was used as an activator of the Wnt signaling pathway, an enhanced expression of $\beta$-catenin was evident. $\beta$-catenin accumulated in the cytoplasm and also translocated to the nucleus. Looking at the CSC characteristics, a dramatic increase in the proliferation, migration and clone formation abilities was observed.
On the other hand, when the pathway was blocked by knocking down $\beta$-catenin, a decrease was observed in the proliferation, clone formation, migration and drug resistance abilities.

\section{Role of Notch pathway}

Ligand proteins binding to the extracellular domain of Notch receptor induce proteolytic cleavage, including a final cleavage operated by a $\gamma$-secretase complex. This releases the active forms of Notch receptors, the intracellular Notch $\left(\operatorname{Notch}^{\mathrm{IC}}\right)$, which translocate to the nucleus and form a complex with a DNA-binding protein resulting in the expression of various target genes. The four Notch family members may have very different and opposing activities in vivo [75-77], which explains why Notch pathway activation can have either oncogenic or tumor suppressor effects. A study found controversy between in vitro and in vivo inhibition of Notch using $\gamma$-secretase inhibitor MRK-003. In vitro, the Notch pathway inhibition decreased cancer cell line NCI-H1299 and NCI-H1435 clonogenic potential and this effect was reversed by expression of a constitutively active form of Notch3. In vivo, there was no evident effect on tumorigenicity from induced expression of a dominant-negative Notch pathway inhibitor. This supports the idea that different Notch isoforms have different roles and suppression of each of them differs from global suppression of Notch signaling [78].

Notch proteins caused a profound growth arrest in SCLC, according to one study [79]. On the other hand, several studies demonstrated the role of Notch-3 in lung cancer cell proliferation. Moreover, inhibition of the Notch3 pathway using a dominantnegative receptor dramatically decreased growth in soft agar [76,77] Hypoxia increases expression of Notch direct downstream genes and the Notch ${ }^{\text {IC }}$ domain interacts with Hypoxia Inducible Factor 1a (HIFlalpha). Consequently, hypoxia, through the Notch signaling pathway, keeps the cell in the undifferentiated state [80].

Eliasz et al. [81] hypothesized a possible cross-talk between Notch-1 and IGF-1 signaling in lung adenocarcinoma. They demonstrated that that Notch-1-mediated pro-survival function in hypoxic lung adenocarcinoma through activation of Akt-1, which in turn inhibits Phosphatase and Tensin (PTEN) homolog expression and induces Insulin-like Growth Factor 1 Receptor (IGF-1R). As a result, hypoxia supports cancer stem cell survival and causes resistance to anticancer therapy.

\section{Targeting CSC Biomarkers and Signaling Pathways for Therapy}

The combination of anti-psychotic drug trifluoperazine with gefitinib has been demonstrated to overcome drug resistance in lung CSCs by targeting CD133/CD44 markers [82].

One study, using FISH in ALDH positive and negative A549, H460 and H1299 cell lines, showed that lung CSCs possess longer telomeres than their differentiated counterparts [83]. Using telomerase inhibitor MST312, it was demonstrated that the response to treatment differs according to the length of telomere, and cells with longer telomeres (H1299>H460, and CSCs>non-CSCs) were more sensitive to MST312mediated cell growth inhibition. A decrease in ALDH positive cells was shown after treatment.

Therapeutic targeting of the Notch pathway in ALDH positive cells resulted in a significant decrease in ALDH positive lung cancer cells, which implicates the Notch pathway in lung cancer stem cell maintenance [53]. According to another study, the inhibition of Wnt1 
or Wnt2 by siRNA or monoclonal antibodies results in apoptosis of NSCLC cell lines [84]. MRK-003, a gamma-secretase inhibitor, was proven to be able to inhibit Notch3 signaling, resulting in inhibition of lung cancer cell lines proliferation and increased apoptosis in vitro and in vivo using mouse xenograft models [85]. GDC-0449 is shown to be effective in inhibiting lung cancer cell lines HCC (adenocarcinoma) and H1339 (small-cell-lung carcinoma) by targeting hedgehog pathway in the side population cells in these cancers. Moreover, it enhanced the effect of cisplatin [86].

CSCs produce SCF that, by binding to c-kit, could stimulate CSC proliferation. Imatinib blocks the ability of SCF to activate c-kit receptors, thus resulting in a profound inhibition of CSC growth. In contrast to CSCs, imatinib had no detectable effect on bulk NSCLC cells due to the lack of the c-kit expression by the vast majority of these cells. As a result, cisplatin-imatinib treatment of NSCLC cells growing in vitro led to potent inhibition of both non-CSCs and CSCs [87]. All these studies point to an effective management of lung cancer subtypes through targeted approach against CSCs.

\section{Conclusions}

CSCs, which are subpopulation of cancer cells, have distinct markers and signaling pathways, play a major role in lung cancer initiation, resistance to chemotherapy and relapse after treatment. Several studies have been conducted to characterize as well as target this population of cells in order to better control the cancer recurrence after chemotherapy. However, several questions remain unanswered. These include better understanding of the exact role of the signaling pathways in normal and malignant stem cells, the interactions between cancer stem cells and the microenvironment and whether targeting the microenvironment will better control the cancer progression. Also, the translation of laboratory research to clinical applications and therapies is the next big challenge. The preliminary information is encouraging and further research on CSCs will broaden our knowledge of lung cancer cell biology and will ultimately improve therapeutic options for the effective clinical management of lung cancer.

\section{References}

1. Siegel R, Naishadham D, Jemal A (2012) Cancer statistics, 2012. CA Cancer J Clin 62: 10-29.

2. Al-Hajj M, Wicha MS, Benito-Hernandez A, Morrison SJ, Clarke MF (2003) Prospective identification of tumorigenic breast cancer cells. Proc Natl Acad Sci USA 100: 3983-3988.

3. Singh SK, Hawkins C, Clarke ID, Squire JA, Bayani J, et al. (2004) Identification of human brain tumour initiating cells. Nature 432: 396-401.

4. Collins AT, Maitland NJ (2006) Prostate cancer stem cells. Eur J Cancer 42: 1213-1218.

5. Carney DN, Gazdar AF, Bunn PA Jr, Guccion JG (1982) Demonstration of the stem cell nature of clonogenic tumor cells from lung cancer patients. Stem Cells 1: 149-164

6. Ho MM, Ng AV, Lam S, Hung JY (2007) Side population in human lung cancer cell lines and tumors is enriched with stem-like cancer cells. Cancer Res 67: 4827-4833.

7. Levina V, Marrangoni AM, DeMarco R, Gorelik E, Lokshin AE (2008) Drugselected human lung cancer stem cells: cytokine network, tumorigenic and metastatic properties. PLoS One 3: e3077.

8. Dean M, Fojo T, Bates S (2005) Tumour stem cells and drug resistance. Nat Rev Cancer 5: 275-284.

9. Mani SA, Guo W, Liao MJ, Eaton EN, Ayyanan A, et al. (2008) The epithelialmesenchymal transition generates cells with properties of stem cells. Cell 133: 704-715

10. Evans MJ, Van Winkle LS, Fanucchi MV, Plopper CG (2001) Cellular and molecular characteristics of basal cells in airway epithelium. Exp Lung Res 27: $401-415$

11. Rock JR, Onaitis MW, Rawlins EL, Lu Y, Clark CP, et al. (2009) Basal cells as stem cells of the mouse trachea and human airway epithelium. Proc Natl Acad Sci USA 106: 12771-12775.

12. Nakajima M, Kawanami O, Jin E, Ghazizadeh M, Honda M, et al. (1998) Immunohistochemical and ultrastructural studies of basal cells, Clara cells and bronchiolar cuboidal cells in normal human airways. Pathol Int 48: 944-953.

13. Giangreco A, Groot KR, Janes SM (2007) Lung cancer and lung stem cells: strange bedfellows? Am J Respir Crit Care Med 175: 547-553.

14. Boers JE, Ambergen AW, Thunnissen FB (1998) Number and proliferation of basal and parabasal cells in normal human airway epithelium. Am J Respir Crit Care Med 157: 2000-2006.

15. Buckpitt A, Chang AM, Weir A, Van Winkle L, Duan X, et al. (1995) Relationship of cytochrome P450 activity to Clara cell cytotoxicity. IV. Metabolism of naphthalene and naphthalene oxide in microdissected airways from mice, rats, and hamsters. Mol Pharmacol 47: 74-81.

16. Stevens TP, McBride JT, Peake JL, Pinkerton KE, Stripp BR (1997) Cell proliferation contributes to PNEC hyperplasia after acute airway injury. Am J Physiol 272: L486-L493.

17. Hong KU, Reynolds SD, Watkins S, Fuchs E, Stripp BR (2004) In vivo differentiation potential of tracheal basal cells: evidence for multipotent and unipotent subpopulations. Am J Physiol Lung Cell Mol Physiol 286: L643-L649.

18. Kim CF, Jackson EL, Woolfenden AE, Lawrence S, Babar I, et al. (2005) Identification of bronchioalveolar stem cells in normal lung and lung cancer. Cell 121: 823-835.

19. Stripp BR, Maxson K, Mera R, Singh G (1995) Plasticity of airway cell proliferation and gene expression after acute naphthalene injury. Am J Physiol 269: L791-L799.

20. Sullivan JP, Minna JD, Shay JW (2010) Evidence for self-renewing lung cancer stem cells and their implications in tumor initiation, progression, and targeted therapy. Cancer Metastasis Rev 29: 61-72.

21. Hong KU, Reynolds SD, Watkins S, Fuchs E, Stripp BR (2004) Basal cells are a multipotent progenitor capable of renewing the bronchial epithelium. Am J Pathol 164: 577-588.

22. Borthwick DW, Shahbazian M, Krantz QT, Dorin JR, Randell SH (2001) Evidence for stem-cell niches in the tracheal epithelium. Am J Respir Cell Mol Biol 24: 662-670.

23. Asselin-Labat ML, Filby CE (2012) Adult lung stem cells and their contribution to lung tumourigenesis. Open Biol 2: 120094.

24. Hong KU, Reynolds SD, Giangreco A, Hurley CM, Stripp BR (2001) Clara cell secretory protein-expressing cells of the airway neuroepithelial body microenvironment include a label-retaining subset and are critical for epithelial renewal after progenitor cell depletion. Am J Respir Cell Mol Biol 24: 671-681.

25. Cruz MH, Sidén A, Calaf GM, Delwar ZM, Yakisich JS (2012) The stemness phenotype model. ISRN Oncol 2012: 392647.

26. Lieber M, Smith B, Szakal A, Nelson-Rees W, Todaro G (1976) A continuous tumor-cell line from a human lung carcinoma with properties of type II alveolar epithelial cells. Int J Cancer 17: 62-70.

27. Justilien V, Regala RP, Tseng IC, Walsh MP, Batra J, et al. (2012) Matrix metalloproteinase-10 is required for lung cancer stem cell maintenance, tumor initiation and metastatic potential. PLoS One 7: e35040.

28. Salnikov AV, Liu L, Platen M, Gladkich J, Salnikova O, et al. (2012) Hypoxia induces EMT in low and highly aggressive pancreatic tumor cells but only cells with cancer stem cell characteristics acquire pronounced migratory potential. PLoS One 7: e46391.

29. La Fleur L, Johansson AC, Roberg K (2012) A CD44high/EGFRlow subpopulation within head and neck cancer cell lines shows an epithelialmesenchymal transition phenotype and resistance to treatment. PLoS One 7: e44071.

30. Peacock CD, Watkins DN (2008) Cancer stem cells and the ontogeny of lung cancer. J Clin Oncol 26: 2883-2889.

31. Maitah MY, Ali S, Ahmad A, Gadgeel S, Sarkar FH (2011) Up-regulation of 
sonic hedgehog contributes to TGF- $\beta 1$-induced epithelial to mesenchymal transition in NSCLC cells. PLoS One 6: e16068.

32. Tellez CS, Juri DE, Do K, Bernauer AM, Thomas CL, et al. (2011) EMT and stem cell-like properties associated with miR-205 and miR-200 epigenetic silencing are early manifestations during carcinogen-induced transformation of human lung epithelial cells. Cancer Res 71: 3087-3097.

33. Castaño Z, Fillmore CM, Kim CF, McAllister SS (2012) The bed and the bugs: interactions between the tumor microenvironment and cancer stem cells. Semin Cancer Biol 22: 462-470.

34. Joyce JA, Pollard JW (2009) Microenvironmental regulation of metastasis. Nat Rev Cancer 9: 239-252.

35. Cirri P, Chiarugi $P$ (2011) Cancer associated fibroblasts: the dark side of the coin. Am J Cancer Res 1: 482-497.

36. Bergfeld SA, DeClerck YA (2010) Bone marrow-derived mesenchymal stem cells and the tumor microenvironment. Cancer Metastasis Rev 29: 249-261.

37. Son BR, Marquez-Curtis LA, Kucia M, Wysoczynski M, Turner AR, et al. (2006) Migration of bone marrow and cord blood mesenchymal stem cells in vitro is regulated by stromal-derived factor-1-CXCR4 and hepatocyte growth factor-cmet axes and involves matrix metalloproteinases. Stem Cells 24: 1254-1264.

38. Rajantie I, IImonen M, Alminaite A, Ozerdem U, Alitalo K, et al. (2004) Adult bone marrow-derived cells recruited during angiogenesis comprise precursors for periendothelial vascular mural cells. Blood 104: 2084-2086.

39. Karnoub AE, Dash AB, Vo AP, Sullivan A, Brooks MW, et al. (2007) Mesenchymal stem cells within tumour stroma promote breast cancer metastasis. Nature 449: 557-563.

40. Qiao L, Xu ZL, Zhao TJ, Ye LH, Zhang XD (2008) Dkk-1 secreted by mesenchymal stem cells inhibits growth of breast cancer cells via depression of Wnt signalling. Cancer Lett 269: 67-77.

41. Yang J, Weinberg RA (2008) Epithelial-mesenchymal transition: at the crossroads of development and tumor metastasis. Dev Cell 14: 818-829.

42. Meng X, Li M, Wang X, Wang Y, Ma D (2009) Both CD133+ and CD133subpopulations of A549 and H446 cells contain cancer-initiating cells. Cancer Sci 100: 1040-1046.

43. Chen YC, Hsu HS, Chen YW, Tsai TH, How CK, et al. (2008) Oct-4 expression maintained cancer stem-like properties in lung cancer-derived CD133-positive cells. PLoS One 3: e2637.

44. Rosner MH, Vigano MA, Ozato K, Timmons PM, Poirier F, et al. (1990) A POUdomain transcription factor in early stem cells and germ cells of the mammalian embryo. Nature 345: 686-692.

45. Bertolini G, Roz L, Perego P, Tortoreto M, Fontanella E, et al. (2009) Highly tumorigenic lung cancer CD133+ cells display stem-like features and are spared by cisplatin treatment. Proc Natl Acad Sci USA 106: 16281-16286.

46. Cui F, Wang J, Chen D, Chen YJ (2011) CD133 is a temporary marker of cancer stem cells in small cell lung cancer, but not in non-small cell lung cancer. Oncol Rep 25: 701-708.

47. Hilbe W, Dirnhofer S, Oberwasserlechner F, Schmid T, Gunsilius E, et al (2004) CD133 positive endothelial progenitor cells contribute to the tumour vasculature in non-small cell lung cancer. J Clin Pathol 57: 965-969.

48. Herpel E, Jensen K, Muley T, Warth A, Schnabel PA, et al. (2011) The cancer stem cell antigens CD133, BCRP1/ABCG2 and CD117/c-KIT are not associated with prognosis in resected early-stage non-small cell lung cancer. Anticancer Res 31: 4491-4500.

49. Russo JE, Hilton J (1988) Characterization of cytosolic aldehyde dehydrogenase from cyclophosphamide resistant L1210 cells. Cancer Res 48: 2963-2968.

50. Liang D, Shi $Y$ (2012) Aldehyde dehydrogenase-1 is a specific marker for stem cells in human lung adenocarcinoma. Med Oncol 29: 633-639.

51. Huang CP, Tsai MF, Chang TH, Tang WC, Chen SY, et al. (2013) ALDHpositive lung cancer stem cells confer resistance to epidermal growth factor receptor tyrosine kinase inhibitors. Cancer Lett 328: 144-151.

52. Lu Y, Thomson JM, Wong HY, Hammond SM, Hogan BL (2007) Transgenic over-expression of the microRNA miR-17-92 cluster promotes proliferation and inhibits differentiation of lung epithelial progenitor cells. Dev Biol 310: 442-453.

53. Sullivan JP, Spinola M, Dodge M, Raso MG, Behrens C, et al. (2010) Aldehyde dehydrogenase activity selects for lung adenocarcinoma stem cells dependent on notch signaling. Cancer Res 70: 9937-9948.

54. An Y, Ongkeko WM (2009) ABCG2: the key to chemoresistance in cancer stem cells? Expert Opin Drug Metab Toxicol 5: 1529-1542.

55. Ross DD, Nakanishi T (2010) Impact of breast cancer resistance protein on cancer treatment outcomes. Methods Mol Biol 596: 251-290.

56. Krishnamurthy P, Ross DD, Nakanishi T, Bailey-Dell K, Zhou S, et al. (2004) The stem cell marker Bcrp/ABCG2 enhances hypoxic cell survival through interactions with heme. J Biol Chem 279: 24218-24225.

57. Ahmed F, Arseni N, Glimm H, Hiddemann W, Buske C, et al. (2008) Constitutive expression of the ATP-binding cassette transporter ABCG2 enhances the growth potential of early human hematopoietic progenitors. Stem Cells 26 810-818.

58. Niu Q, Wang W, Li Y, Ruden DM, Wang F, et al. (2012) Low molecular weight heparin ablates lung cancer cisplatin-resistance by inducing proteasomemediated ABCG2 protein degradation. PLoS One 7: e41035.

59. Jaggupilli A, Elkord E (2012) Significance of CD44 and CD24 as cancer stem cell markers: an enduring ambiguity. Clin Dev Immunol 2012: 708036.

60. Du L, Wang H, He L, Zhang J, Ni B, et al. (2008) CD44 is of functional importance for colorectal cancer stem cells. Clin Cancer Res 14: 6751-6760.

61. Bapat SA (2010) Human ovarian cancer stem cells. Reproduction 140: 33-41.

62. Lee HJ, Choe G, Jheon S, Sung SW, Lee CT, et al. (2010) CD24, a nove cancer biomarker, predicting disease-free survival of non-small cell lung carcinomas: a retrospective study of prognostic factor analysis from the viewpoint of forthcoming (seventh) new TNM classification. J Thorac Oncol 5 : 649-657.

63. Slomiany MG, Dai L, Tolliver LB, Grass GD, Zeng Y, et al. (2009) Inhibition of Functional Hyaluronan-CD44 Interactions in CD133-positive Primary Human Ovarian Carcinoma Cells by Small Hyaluronan Oligosaccharides. Clin Cancer Res 15: 7593-7601.

64. Leung EL, Fiscus RR, Tung JW, Tin VP, Cheng LC, et al. (2010) Non-small cell lung cancer cells expressing CD44 are enriched for stem cell-like properties. PLoS One 5: e14062.

65. Watkins DN, Berman DM, Burkholder SG, Wang B, Beachy PA, et al. (2003) Hedgehog signalling within airway epithelial progenitors and in small-cell lung cancer. Nature 422: 313-317.

66. Gialmanidis IP, Bravou V, Amanetopoulou SG, Varakis J, Kourea H, et al. (2009) Overexpression of hedgehog pathway molecules and FOXM1 in nonsmall cell lung carcinomas. Lung Cancer 66: 64-74.

67. Zhang Y, Kalderon D (2001) Hedgehog acts as a somatic stem cell factor in the Drosophila ovary. Nature 410: 599-604.

68. Gupta S, Takebe N, Lorusso P (2010) Targeting the Hedgehog pathway in cancer. Ther Adv Med Oncol 2: 237-250.

69. Reya T, Morrison SJ, Clarke MF, Weissman IL (2001) Stem cells, cancer, and cancer stem cells. Nature 414: 105-111.

70. Rubin LL, de Sauvage FJ (2006) Targeting the Hedgehog pathway in cancer Nat Rev Drug Discov 5: 1026-1033

71. Willert K, Jones KA (2006) Wnt signaling: is the party in the nucleus? Genes Dev 20: 1394-1404.

72. He B, Barg RN, You L, Xu Z, Reguart N, et al. (2005) Wnt signaling in stem cells and non-small-cell lung cancer. Clin Lung Cancer 7: 54-60.

73. Uematsu K, He B, You L, Xu Z, McCormick F, et al. (2003) Activation of the Wnt pathway in non small cell lung cancer: evidence of dishevelled overexpression. Oncogene 22: 7218-7221.

74. Teng $Y$, Wang $X$, Wang $Y$, Ma D (2010) Wnt/beta-catenin signaling regulates cancer stem cells in lung cancer A549 cells. Biochem Biophys Res Commun 392: 373-379.

75. Shimizu K, Chiba S, Saito T, Kumano K, Hamada Y, et al. (2002) Functiona diversity among Notch1, Notch2, and Notch3 receptors. Biochem Biophys Res Commun 291: 775-779.

76. Fan X, Mikolaenko I, Elhassan I, Ni X, Wang Y, et al. (2004) Notch1 and notch2 have opposite effects on embryonal brain tumor growth. Cancer Res 64: 77877793. 
Citation: Salama R, Tang J, Gadgeel SM, Ahmad A, Sarkar FH (2012) Lung Cancer Stem Cells: Current Progress and Future Perspectives. J Stem Cell Res Ther S7:007. doi:10.4172/2157-7633.S7-007

77. Graziani I, Eliasz S, De Marco MA, Chen Y, Pass HI, et al. (2008) Opposite effects of Notch-1 and Notch-2 on mesothelioma cell survival under hypoxia are exerted through the Akt pathway. Cancer Res 68: 9678-9685.

78. Osanyingbemi-Obidi J, Dobromilskaya I, Illei PB, Hann CL, Rudin CM (2011) Notch signaling contributes to lung cancer clonogenic capacity in vitro but may be circumvented in tumorigenesis in vivo. Mol Cancer Res 9: 1746-1754.

79. Sriuranpong V, Borges MW, Ravi RK, Arnold DR, Nelkin BD, et al. (2001) Notch signaling induces cell cycle arrest in small cell lung cancer cells. Cancer Res 61: 3200-3205.

80. Gustafsson MV, Zheng X, Pereira T, Gradin K, Jin S, et al. (2005) Hypoxia requires notch signaling to maintain the undifferentiated cell state. Dev Cell 9: 617-628.

81. Eliasz S, Liang S, Chen Y, De Marco MA, Machek O, et al. (2010) Notch-1 stimulates survival of lung adenocarcinoma cells during hypoxia by activating the IGF-1R pathway. Oncogene 29: 2488-2498.

82. Yeh CT, Wu AT, Chang PM, Chen KY, Yang CN, et al. (2012) Trifluoperazine an antipsychotic agent, inhibits cancer stem cell growth and overcomes drug resistance of lung cancer. Am J Respir Crit Care Med 186: 1180-1188.

83. Serrano D, Bleau AM, Fernandez-Garcia I, Fernandez-Marcelo T, Iniesta P et al. (2011) Inhibition of telomerase activity preferentially targets aldehyde dehydrogenase-positive cancer stem-like cells in lung cancer. Mol Cancer 10 96.

84. He B, You L, Uematsu K, Xu Z, Lee AY, et al. (2004) A monoclonal antibody against Wnt-1 induces apoptosis in human cancer cells. Neoplasia 6: 7-14.

85. Konishi J, Kawaguchi KS, Vo H, Haruki N, Gonzalez A, et al. (2007) Gammasecretase inhibitor prevents Notch3 activation and reduces proliferation in human lung cancers. Cancer Res 67: 8051-8057.

86. Tian F, Mysliwietz J, Ellwart J, Gamarra F, Huber RM, et al. (2012) Effects of the Hedgehog pathway inhibitor GDC-0449 on lung cancer cell lines are mediated by side populations. Clin Exp Med 12: 25-30.

87. Levina V, Marrangoni A, Wang T, Parikh S, Su Y, et al. (2010) Elimination of human lung cancer stem cells through targeting of the stem cell factor-c-kit autocrine signaling loop. Cancer Res 70: 338-346.
This article was originally published in a special issue, Cancer Stem Cells handled by Editor(s). Fazlul Hoque Sarkar, Wayne State University, USA, Asfar Sohail Azmi, Wayne State University, USA 